\title{
Littératures et déchirures, sous la direction de Clément Dili Palaï et Daouda Pare
}

\section{Alessandro Corio}

\section{(2) OpenEdition}

1 Journals

\section{Edizione digitale}

URL: http://journals.openedition.org/studifrancesi/8384

DOI: 10.4000/studifrancesi.8384

ISSN: 2421-5856

\section{Editore}

Rosenberg \& Sellier

\section{Edizione cartacea}

Data di pubblicazione: 1 mai 2009

Paginazione: 214

ISSN: 0039-2944

\section{Notizia bibliografica digitale}

Alessandro Corio, «Littératures et déchirures, sous la direction de Clément Dili Palaï et Daouda Pare»,

Studi Francesi [Online], 157 (LIII | I) | 2009, online dal 30 novembre 2015, consultato il 12 janvier 2021. URL: http://journals.openedition.org/studifrancesi/8384; DOI: https://doi.org/10.4000/studifrancesi. 8384

Questo documento è stato generato automaticamente il 12 janvier 2021.

\section{(c) $(1) \ominus$}

Studi Francesi è distribuita con Licenza Creative Commons Attribuzione - Non commerciale - Non opere derivate 4.0 Internazionale. 


\title{
Littératures et déchirures, sous la direction de Clément Dili Palaï et Daouda Pare
}

\author{
Alessandro Corio
}

\section{NOTIZIA}

Littératures et déchirures, sous la direction de Clément DILI PALAÏ et Daouda PARE, avec une préface de Romuald Fonkoua, Paris, L’Harmattan, 2008 («Études Africains»), pp. 190.

1 Questa notevole miscellanea, curata da Clément Dili Palaï e Daouda Pare dell'Università di Ngaoundéré (Camerun), affronta, con approccio comparatista e interdisciplinare, il rapporto tra le letterature (prevalentemente, ma non esclusivamente, in ambito francofono) e le «déchirures». Innanzitutto, quale definizione è proponibile di questo termine, semanticamente così ricco? «Il s'agit d'un état», affermano i due curatori, «d'une conscience, d'une situation dans laquelle l'individu se trouve en discordance avec lui-même ou avec son environnement. La déchirure construit et prolonge un état de manque, une dysphorie permanente. En ce sens, elle nourrit et fortifie l'angoisse de vivre» (p. 8). Un approccio tutto in negativo, insomma, che però, come vedremo, risulta suscettibile di un insieme di sviluppi analitici e di potenzialità dinamiche affatto positive. La dimensione della lacerazione, interiore, collettiva, sociale, risulta innanzitutto strettamente collegata alla complessa questione dell'identità, della sua costruzione, definizione e crisi. La letteratura, d'altra parte, si è sempre mostrata come un campo privilegiato di esplorazione di queste tensioni, aprendo le porte a tutte le forme di espressione che permettono all'uomo di dirsi, di cercarsi, soprattutto in un mondo sempre più segnato dalla paura dell'altro, e quindi di se stessi, dalla chiusura $\mathrm{e}$ dall'accumulazione meramente materiale. Una lacerazione, affermano i curatori, suppone, in effetti, la pre-esistenza di un'unità, di un'identità, di un'armonia dell'essere e dell'esistenza, cosa di cui, aggiungiamo noi, il pensiero e la letteratura contemporanei 
ci hanno abituato a diffidare. La lacerazione risulta perciò, in un certo senso, originaria e costitutiva della stessa esperienza umana.

Gli autori e le opere analizzati nei dodici saggi qui raccolti appartengono a spazi letterari differenziati geograficamente e linguisticamente, dall'Europa all'Africa subsahariana, dal Maghreb alle Antille, e si va da autori celebri, come Perec, Tournier, Glissant, Ben Jelloun, Coetzee, Hampâté Bâ, ad autori meno noti come Dahirou Yaya, Yodi Karone, Baskouda e Ferrandi. Le tematiche al centro della riflessione, connesse al tema principale delle lacerazioni, sono quelle della sofferenza morale, del trauma legato a circostanze storiche violente, al colonialismo, alla tratta degli schiavi, all'esilio, alla ricerca di un passato sommerso o rimosso, che non si dà, come nel caso di Édouard Glissant, in forme fisse, bensì dinamiche e connesse ad un desiderio che riattiva in continuazione il proprio oggetto, ampliando così il proprio tessuto relazionale. Amadou Hampâté Bâ e Léonora Miano vengono accostati nell'analisi delle lacerazioni identitarie come conseguenza delle fratture postcoloniali e, più in generale, emerge come le lacerazioni, individuali o collettive, risultino pressoché stabilmente connesse al rapporto difficile che il soggetto intrattiene con l'alterità.

La frattura può pertanto mostrare delle potenzialità "positive", aprendo la strada alla costruzione di un futuro differente, laddove il conflitto iniziale si mostra in grado di aprire degli spazi di scambio non conflittuale, etico, un superamento di quella dialettica che distanzia irrevocabilmente il Medesimo dall'Altro, mettendoli perennemente in reciproco conflitto. Lo mostra bene il saggio dedicato alla lettura di Michel Tournier, sotto il prisma di Hegel e di Kojève, dove l'autore rileva come il celebre romanzo Vendredi ou les limbes du Pacifique offra una versione della dialettica hegeliana che sfugge alla contrapposizione e al conflitto frontale, aprendo ad una visione alternativa del rapporto con l'alterità.

In fin dei conti, si afferma sempre nell'introduzione, la questione della «déchirure» appare strettamente connessa a quella dell'«identité», nella misura in cui l'uomo, quale che sia la sua posizione storica o sociale, è chiamato a costruire un rapporto col proprio spazio-tempo. I vari articoli esplorano la questione sotto diverse angolature, che si tratti dello spazio urbano, di quello della guerra e dell'infanzia, della complessa scrittura identitaria all'opera nello spazio letterario autobiografico. Le differenti prospettive sembrano perciò convergere verso un assunto unitario: l'identità deve essere ripensata, non nei termini di un ripiegamento su se stessi o di un confrontoconflitto con l'altro, bensì nei termini di un'integrazione - concetto peraltro quanto mai equivoco - che permetta all'uomo di vivere in un mondo più permeabile agli scambi ed alle relazioni, e di concepire così nuovi modi per vivere assieme. 